\title{
Haematology and the extracorporeal circulation
}

\author{
A. A. SHARP AND M. J. EGGLETON \\ From the Nuffield Department of Surgery, Oxford
}

SYNOPSIS The experience gained in the investigation of 100 cases of cardiac surgery treated by use of extracorporeal circulation has shown that certain simple laboratory tests suffice to detect induced defects in the blood and to guide therapy. These tests have been devised to detect the level of circulating heparin during perfusion; the presence of residual heparin following perfusion; the existence of a qualitative or quantitative fibrinogen deficiency; excessive fibrinolysis. Any of the latter three abnormalities alone or together have caused excessive immediate post-operative blood loss. Specific therapy has not been found to be necessary unless severe bleeding occurs.

The design and use of the many types of extracorporeal circulation used for open-heart surgery should be an anathema to any haematologist or bio-rheologist. All pump blood, artifically anticoagulated, circulates through a variety of reservoirs, tubes, and oxygenators which expose this blood to a variety of insults-foreign surfaces, e.g., plastic tubing, stainless steel discs, turbulent flow, compression by pumps, frothing, and huge air interfaces. It is surprising indeed that these circulations do work and cause comparatively little trouble. However, in the occasional case and quite unpredictably the blood is damaged and severe post-operative bleeding results. Many reasons have been advanced as an explanation: thrombocytopenia, fibrinolysis, fibrinogen deficiency, circulating anticoagulants, and residual heparin (von Kaulla and Swan, 1958; Nilsson and Swedberg, 1959; Perkins, Osborn, and Gerbode, 1959; Rothnie and Kinmonth, 1960; Sharp, Excell, Salzman, and Thorup, 1961). It is therefore pertinent to review the haematology of extracorporeal circulation in open-heart surgery in the light of the experience gained during the routine investigation of 100 patients with congenital or acquired heart lesions operated on in the Nuffield Department of Surgery during the past four years. In 77 operations the technique of profound hypothermia to $8^{\circ} \mathrm{C}$. has been employed (Gunning, 1961), in 14 moderate hypothermia, and nine operations were carried out at normal body temperature.

\section{MATERIALS}

PUMP The Mayo-Gibbon pump with a vertical screen oxygenator, with a priming volume of 10 to 12 pints was used.

HEPARIN Boots Crystalline (cresol-free).
HEPARINIZED BLOOD Heparin, $30 \mathrm{mg}$. per $500 \mathrm{ml}$. blood.

eDglugate $\mathrm{Na}_{2} \mathrm{H}_{2}$ E.D.T.A.- $\mathrm{Na}_{3} \mathrm{H}$ E.D.T.A. mixture (ethylene diamine tetra-acetic acid)

$0.080 \mathrm{M} p \mathrm{H} 6.8(1.1 \mathrm{mM}$ E.D.T.A.).....13.75 ml.

Sodium gluconate $0 \cdot 167 \mathrm{M} . \ldots \ldots \ldots \ldots .10 .00 \mathrm{ml}$.

Magnesium chloride $0.10 \mathrm{M} \ldots \ldots \ldots \ldots .1 .5 \mathrm{ml}$.

Glucose $1.5 \%$ as $50 \%$ solution........ $3.0 \mathrm{ml}$.

Water to ..................... $50.0 \mathrm{ml}$.

$p \mathrm{H}$ after autoclaving $6 \cdot 7$

RHEOMACRODEX (Pharmacia) $10 \%$ in saline.

POLYBRENE (Abbot) Hexadimethrine bromide.

ePSILON-AMINO-CAProic ACID (E.A.C.A.) Kabi Pharmaceuticals (London).

PROTAMINE SULPHATE $1 \%$ (вOOTS).

METHODS

Platelets were counted by the method of Brecher and Cronkite (1950).

THROMBIN CLOTTING TIME Human thrombin (FibrindexOrtho), $0.1 \mathrm{ml}$., 20 units $/ \mathrm{ml}$, was added to $0.5 \mathrm{ml}$. plasma and the clotting time recorded.

FIBRINOGEN TITRE (SHARP, HOWIE, BIGGS, AND METHUEN, 1958) Doubling dilutions of citrate plasma (1/2 to $1 / 128)$ in saline are prepared in $0.5 \mathrm{ml}$. amounts. To each dilution $0.1 \mathrm{ml}$. thrombin (Fibrindex, Ortho) is added. After 10 minutes each tube is examined for the presence or absence of a fibrin clot and for the quality of the clot. The titre is recorded as the highest dilution in which a fibrin clot can be detected. Normal is $1 / 64$ to $1 / 128$, mild defect, $1 / 16$ to $1 / 32$, moderate defect, $1 / 4$ to $1 / 8$, and severe defect, 0 to $1 / 2$. 
TEST FOR SIGNIFICANT FIBRINOLYSIS The fibrinogen titre is carried out as above. A second row of tubes is prepared but this time with doubling dilutions of citrate plasma in a solution of E.A.C.A. (1 mg. $/ 1 \mathrm{ml}$.). All tubes are clotted with thrombin and examined after 15 minutes' and 30 minutes' incubation at $37^{\circ} \mathrm{C}$.

Excessive lysis is considered to be present if the saline titre is two dilutions lower than the E.A.C.A. titre in 30 minutes or if all the clots in the saline titre lyse in 60 minutes.

PROTAMINE SULPHATE POLYBRENE TITRATION (MODIFICATION OF THE METHOD OF JAQUES, 1943) A stock solution of protamine sulphate or polybrene is made to give a concentration of $20 \mathrm{mg} . \%$. Dilutions of it are made to give a range of concentrations of 20 to $1 \mathrm{mg} . \%$ in $1 \mathrm{mg}$. stages. Test plasma, $0.1 \mathrm{ml}$., is added to $0.1 \mathrm{ml}$. of each concentration, together with $0.1 \mathrm{ml}$. saline and $0.1 \mathrm{ml}$. human thrombin $40 \mathrm{u}$. $/ \mathrm{ml}$. and the clotting time recorded. At the level of protamine or polybrene when heparin is neutralized the clotting time will shorten rapidly. This has been termed the 'break point' (Fig. 1). The plasma heparin can, therefore, be expressed as milligrams $\%$ protamine or polybrene equivalent.

Blood heparin equivalent $=$ plasma heparin equivalent

$$
\times \frac{100-\text { haematocrit }}{100}
$$

HAEMOLYSIS IN VITRO A modification of the method of Stewart and Surridge (1959) was used.

Heparinized fresh blood, $5 \mathrm{ml}$., is placed in a $20 \mathrm{~cm}$. length of the plastic tubing to be tested. This tubing is formed into a circle and the junction sealed with an exterior cuff. This tubing is placed on a turntable set at $20^{\circ}$ from the horizontal and rotating at 3 to 4 r.p.m. The blood contained in the tube is allowed to flow for one hour at room temperature. The blood is then collected and the supernatant plasma examined for the amount of free haemoglobin.

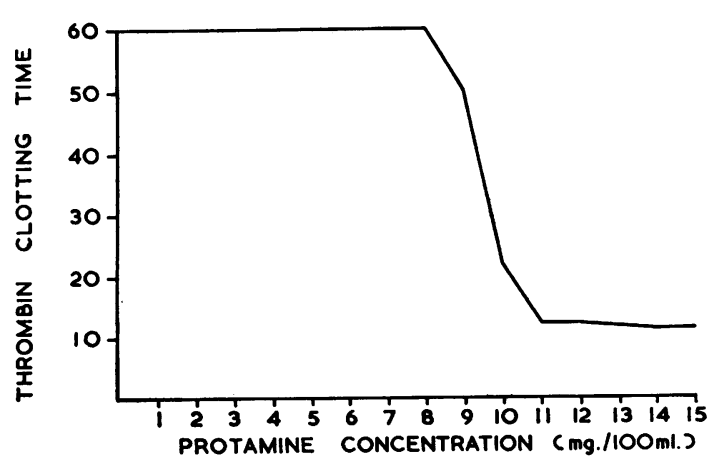

FIG. 1. Titration of blood heparin by protamine sulphate. The sudden shortening of the thrombin clotting time ('break-point') indicates the amount of heparin present in protamine equivalent, in this example $9 \mathrm{mg} .1100 \mathrm{ml}$.
PREPARATION OF EDGLUGATE BLOOD BEFORE PRIMING

The priming blood is collected on the day before the operation. In the hour before priming the pump $30 \mathrm{mg}$. heparin and $5 \mathrm{ml} .10 \%$ calcium gluconate are added to each bottle in this order.

\section{RESULTS}

PRE-OPERATIVE CHECK Fourteen patients were found to have long bleeding times (more than seven minutes) and in six a positive family history and a history of previous bleeding were obtained. The $\vec{\sigma}$ A.H.G. assay in all instances was normal and no other defect of plasma coagulation factors was dis- $G$ covered.

In each instance steroid therapy for one week before operation returned the bleeding time to $\vec{z}$ normal, and as an extra precaution fresh heparinized blood was used instead of stored Edglugate blood. In no instance was there any abnormal postoperative blood loss.

In one patient marked thrombocytopenia was $\vec{\varphi}$ found in association with a high packed red cell $\omega$ volume due to secondary polycythaemia.

Recently each patient has had a careful personal and family history taken to determine whether or not any abnormal bleeding tendency exists. This step has been found to be of increasing importance, as it is emerging that mild coagulation defects, e.g., haemophilia, Christmas disease, and von Willebrand's disease, can only be detected by specific assay systems, and are not detected by routine screening tests.

ASSESSMENT OF HEPARIN LEVEL DURING OPERATION The heparin level is checked on three occasions by protamine sulphate or polybrene titration: 1 pump blood after priming; 2 pump-patient mixed blood at the start of perfusion; 3 during the rewarm phase approximately 30 minutes before the end of perfusion.

The patient receives $3 \mathrm{mg}$. heparin $/ \mathrm{kg}$. body weight $\mathrm{N}$ and the pump blood contains $6 \mathrm{mg} . / 100 \mathrm{ml}$. These $\mathrm{N}$ amounts should be adequate for a two-hour per- $N$ fusion but some variation in the heparin levels has $\omega$ been found. On two occasions inexplicably low levels of heparin ( $1 \mathrm{mg} . / 100 \mathrm{ml}$.) have been found, and $\stackrel{0}{\mathrm{C}}$ extra heparin has had to be given to restore the $\$$ level to the target of 2 to $3 \mathrm{mg}$. \%

The heparin level should not be allowed to drop below $2 \mathrm{mg}$. $/ 100 \mathrm{ml}$. during perfusion. The average fall during perfusion has been 1 to $1.5 \mathrm{mg} . / 100 \mathrm{ml}$. $\frac{\rho}{\Phi}$ per two-hour perfusion. 
POLYBRENE OR PROTAMINE NEUTRALIZATION OF HEPARIN Either polybrene or protamine sulphate has been given at the end of perfusion to neutralize the total calculated dose of heparin that the patient received by injection and from the pump blood. This calculated level has been approximately $4 \mathrm{mg}$. $\%$, allowing for a total blood volume of $80 \mathrm{ml} . / \mathrm{kg}$. body weight. When the antidote was given to neutralize the amount of titratable heparin left in the blood at the end of perfusion, it was found to be inadequate and detectable residual heparin remained.

RESIDUAL HEPARIN It has been found to be of prime importance to ensure that at the end of perfusion the last trace of heparin is neutralized, as this has caused excessive and immediate severe post-operative blood loss.

The thrombin clotting time of plasma prepared from blood collected after the theoretical neutralizing polybrene dose has been given has proved a simple and effective method of detecting residual heparin. If it was found to be more than five seconds longer than the pre-perfusion thrombin clotting time, then the test was repeated with added polybrene or protamine $(1 \mathrm{mg} . / 100 \mathrm{ml}$.). If this latter step shortened the clotting time, residual heparin was assumed to be present and a further dose of the antidote given. If polybrene or protamine had no effect, then the prolongation was considered to be due to fibrinfibrinogen breakdown products in excess amounts (Latallo, Fletcher, Alkjaersig, and Sherry, 1962).

Significant amounts of residual heparin have been found in 25 cases. In the majority excessive bleeding occurred and was stopped immediately by giving an extra dose of the antidote.

DEFIBRINATION AND FIBRINOLYSIS Towards the end of perfusion a sample is taken to detect any significant defibrination by the fibrinogen titre test. Similarly the post-polybrene sample is examined both for evidence of defibrination and also for evidence of significant fibrinolysis, i.e., lysis of such severity that it is likely to do the patient harm.

Twenty-nine cases showed defibrination (20 moderate, nine severe). In eight, bleeding occurred. Twenty cases showed moderate, and 24 severe, lysis (Table I). Defibrination and fibrinolysis have been associated in some cases but each can develop separately (Table II) and in 12 cases treatment

TABLE I

DEFIBRINATION AND FIBRINOLYSIS

\begin{tabular}{lccc} 
Defect & Nil & Moderate & Severe \\
\hline Defibrination & 59 & 20 & 9 \\
Fibrinolysis & 44 & 20 & 24
\end{tabular}

TABLE II

CORRELATION OF DEFIBRINATION AND FIBRINOLYSIS

\begin{tabular}{lccc} 
Defibrination & \multicolumn{2}{l}{ Fibrinolysis } & \\
\cline { 2 - 4 } & Moderate & Severe & Nil \\
\hline Moderate & 5 & 11 & 4 \\
Severe & 2 & 4 & 3 \\
None & 13 & 9 & 36
\end{tabular}

was given, in eight because of severe bleeding and in four because of a severe deficiency of fibrinogen and excessive lysis. Seven cases received doses of $5 \mathrm{~g}$. fibrinogen to raise the fibrinogen levels. Three cases were also given epsilon-amino-caproic acid (E.A.C.A.) because of failure to respond to fibrinogen; two patients received E.A.C.A. alone (Table III). In eight cases excessive bleeding was attributed to defibrination with excessive lysis, and in seven therapy was immediately effective (Table III).

\section{TABLE III}

TREATMENT

\begin{tabular}{lccc} 
& Total Treated & Bleeding & Not Bleeding \\
\hline Fibrinogen & 7 & 4 & 3 \\
Fibrinogen + E.A.C.A. & 3 & 3 & 0 \\
E.A.C.A. & 2 & 1 & 1
\end{tabular}

HAEMOLYSIS This in our experience has not been a problem, although in one case a calculated $350 \mathrm{ml}$. of blood lysed in the early stages of perfusion. However, perfusion and surgery proceeded normally and renal function was not impaired.

Various types of plastic tubing are offered by several manufacturers for the extracorporeal circulation, and it is difficult to determine which is suitable. Using a modification of the method of Stewart and Surridge (1959), it has been possible to assess the haemolysis factor of various plastics and thus to select the best available.

PLATELETS In every case the platelet count dropped during perfusion (Fig. 2), and this tendency was increased by the use of hypothermia. Immediately after perfusion the platelet count has risen, only to fall again in the next 12 hours to a level similar to that reached during perfusion. It has returned to normal levels one to 10 days after operation.

RHEOMACRODEX In the last 28 cases low-molecular dextran has been used to dilute the pump blood in a dose of $25 \mathrm{ml} . / \mathrm{kg}$., as this material is believed to improve perfusion by reversing any tendency of the red cells to sludge and by improving co-axial flow in small blood vessels. When these 28 cases are compared with the 28 previous cases perfused in a 


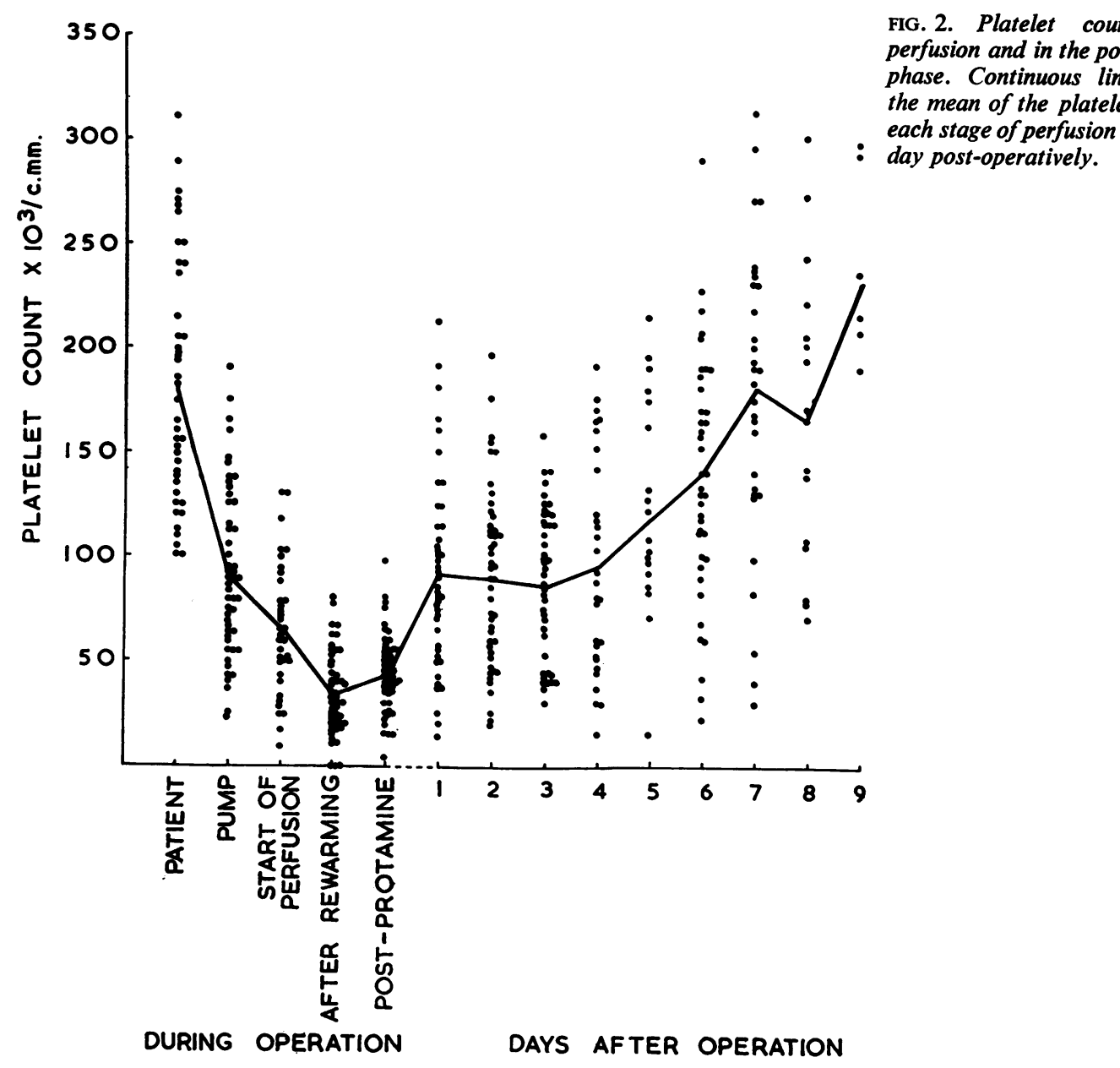

similar way, the following differences were apparent: Saving of blood for priming the pump to the extent of 1 to 2 pints per operation; improved temperature gradients between various tissues during hypothermia; a post-operative diuresis has occurred in every case. The severity of defibrination and lysis has decreased significantly since this material has been used and the number of cases requiring specific treatment has been reduced (Table IV). Although the thrombocytopenia occurring during perfusion has not improved, the post-operative return to normal has been quicker (Table IV).

Rheomacrodex has been criticized for increasing the operative blood loss (Breckenridge and Walker, 1963) but in the present series, while the operative and immediate excessive post-operative loss has not been increased and in fact has decreased, the amount of blood draining from the chest cavity in the first six hours after operation has increased.
TABLE IV

EFFECTS OF RHEOMACRODEX IN 28 CASES WITH RHEOMACRODEX AND 28 WITHOUT RHEOMACRODEX

\begin{tabular}{|c|c|c|}
\hline Abnormality & $\begin{array}{l}\text { With } \\
\text { Rheomacrodex }\end{array}$ & $\begin{array}{l}\text { Without } \\
\text { Rheomacrodex }\end{array}$ \\
\hline $\begin{array}{l}\text { Defibrination moderate or severe } \\
\text { Fibrinolysis severe } \\
\text { Treatment of excessive bleeding } \\
\text { Marked haemolysis }\end{array}$ & $\begin{array}{l}2 \\
1 \\
2 \\
2\end{array}$ & $\begin{array}{r}15 \\
6 \\
8 \\
1\end{array}$ \\
\hline $\begin{array}{l}\text { Platelet count } \\
\text { Mean } \\
\text { Range }\end{array}$ & $\begin{array}{l}45,000 / \text { c.mm. } \\
19,000-80,000 \\
\text { per c. } \mathrm{mm} \text {. }\end{array}$ & $\begin{array}{l}39,000 / \text { c.mm. } \\
0-98,000 \text { per } \\
\text { c. mm. }\end{array}$ \\
\hline $\begin{array}{l}\text { Return of platelet count to normal } i \\
\text { Mean } \\
\text { Range }\end{array}$ & $\begin{array}{c}\text { in days } \\
2 \cdot 8 \\
1-8\end{array}$ & $\begin{array}{l}4 \cdot 2 \\
1-10\end{array}$ \\
\hline
\end{tabular}

POST-OPERATIVE ANAEMIA Red cells have been damaged during perfusion so that their survival has $\frac{}{D}$ been diminished. However, while post-operative 
anaemia has been found in several cases, it has been mild.

No case of post-operative haemolytic anaemia has been encountered following the use of Teflon to repair septal defects.

HOMOLOGOUS SERUM JAUNDICE This has been a disturbing feature in this series. Five patients became jaundiced two to three months after perfusion and three died. In relation to the total numbers of donors used this incidence (approximately two cases $/ 1,000$ pints of blood) is close to the expected. However, these patients would appear to be more susceptible to this virus than other groups of patients receiving large volumes of blood, as the mortality in this series has been high.

OTHER COAGULATION FACTORS No significant depletion of other coagulation factors has been found, although careful assays of specific factors have not been done since the first few cases, as their results were considered to be modified by the presence of heparin or the heparin-polybrene, heparin-protamine sulphate complexes in the post-operative period.

POST-OPERATIVE ANTICOAGULANTS Heparin should not be given in the week immediately following operation. Occasional patients who have received Dindevan have shown increased sensitivity to the drug and the initial dose has produced a dramatic fall of the 'prothrombin complex' to very low and dangerous levels.

POST-OPERATIVE PERIOD If no bleeding has occurred post-operatively no further testing has appeared necessary, apart from daily haemoglobin estimations and platelet counts until the latter have returned to normal.

\section{DISCUSSION}

The outcome of successful cardiac surgery can be jeopardized by the use of extracorporeal perfusion if this procedure so damages the blood that the perfused tissues are injured, or if the haemostatic mechanism fails to operate at the end of perfusion. Technical mismanagement of the pump during perfusion will damage the blood, alter the blood chemistry, and produce tissue anoxia. Careless control of temperature of the heat exchanger can produce a disastrous alteration of blood proteins, and the indiscriminate use of the pump sucker line can cause excessive haemolysis and promote defibrination and lysis. The greatest hazard has been the severe, sudden post-operative blood loss from all cut surfaces which, when it occurred, developed immediately after perfusion ceased and the antidote had been given. The factor most commonly responsible for such haemorrhage has been unneutralized heparin even when present in only trace amounts. The simple thrombin clotting time test has proved very reliable for detecting the presence of heparin. If this clotting time is prolonged or shortened by polybrene, protamine sulphate, or toluidine blue in small concentration $(1 \mathrm{mg} . / 100 \mathrm{ml}$.) heparin is certainly present in the blood. If it is not shortened, then the presence of fibrinogen-fibrin degradation products, which appear whenever defibrination or fibrinolysis occur, should be suspected. This finding agrees with the observations of Rothnie and Kinmonth (1960). The neutralization of heparin with protamine or polybrene in amounts equivalent to the titratable heparin at the end of perfusion has been shown to be unsuccessful, and the dose of antidote has had to be equivalent to the total calculated and not titrated heparin in the patient's blood volume at the start of perfusion. Why this should be so is difficult to explain, but it must be assumed that some heparin quickly escapes into the extravascular fluid where it remains until the blood heparin is neutralized. The return of this extravascular heparin must take place immediately this is done. Delayed heparin rebound has never been detected.

Defibrination or excessive fibrinolysis or both have also been associated with severe haemorrhage in the immediate post-operative period. Simple tests can detect and quantitate these defects quickly, and the haematologist can warn the surgeon of impending trouble, or in consultation advise as to the appropriate therapy and assess its results. Fibrinolysis could be detected in the majority of cases and is inevitable in blood perfusing damaged tissues, in which a certain amount of fibrinogen is being precipitated or converted to fibrin. This activation of fibrinolysis is probably nature's way of protecting the body from the effects of intravascular fibrin formation, and its presence should be considered as beneficial to the host. However, occasionally excessive and violent lysis has developed which was so severe that it was likely to harm the patient. The test described for detecting this excessive lysis is semi-quantitative and appears to provide a rough but effective guide to the presence of severe fibrinolysis. Tests, such as Euglobulin lysis, are too sensitive to be a guide to the presence of dangerous lysis. However, even if violent lysis is found it should not be neutralized unless it is obvious that it is causing excessive and dangerous blood loss. If lysis is left untreated it is rare to find any detectable activity one hour after perfusion. Patients whose blood has shown severe defibrination or lysis and who have not bled, have been treated, but it is 
now our opinion that there is no need to treat such laboratory defects, however severe, if no bleeding develops. This view is supported by observations by Reid, Chan, and Thean (1963) that the state of defibrination by itself does the patient no harm. The transfusion of $5 \mathrm{~g}$. concentrated fibrinogen will usually correct severe fibrinogen deficiency, whether it exists alone or in association with excessive lysis. However, if ineffective, and active lysis can be demonstrated, E.A.C.A. therapy is indicated $(5 \mathrm{~g}$. intravenously). Fibrin-fibrinogen degradation products if present do not require specific treatment unless associated with defibrination or excessive fibrinolysis. It must be remembered, however, that these products are known to interfere with the conversion of fibrin monomer to fibrin polymer (Latallo et al., 1962). They are detected by their pseudo-antithrombin activity and can produce a qualitative rather than a quantitative fibrinogen deficiency, which may cause bleeding and can be corrected by fibrinogen therapy. It must be stressed that E.A.C.A., used to neutralize excessive fibrinolysis, must never be given once the chest is closed, as any subsequent accumulation of blood in the thoracic cavity is likely to clot and this clot, because it will not lyse, can only organize.

Excessive haemolysis has not done any apparent damage, although the gross haemolysis that occurred on one occasion might have been expected to do so. One is tempted to speculate as to whether the high heparin level in the blood protected the patient from the usual consequences of such a degree of lysis.

The induced thrombocytopenia alarmed at first, until it was realized that it did not appear to cause bleeding. Transfusion of platelet concentrates has never been necessary but this step might be indicated if an initial very low platelet count was found before operation. If bleeding has occurred post-operatively, fresh (less than six hours' old) platelet-rich blood has been given. This blood can be used in a slow drip to replace normal drainage if no excessive bleeding takes place. The thrombocytopenia induced during perfusion is thought to be the result $o$ three mechanisms: 1 The sequestration of platelets in the tissues, a mechanism accentuated by hypothermia, but which is reversible; 2 removal of platelet clumps by the filters or by their adherence to the lower end of the oxygenator screens at the blood-gas interface; 3 the utilization of large numbers of platelets in the damaged tissues.

The use of rheomacrodex has been advantageous. Episodes of marked defibrination and lysis have decreased significantly, as has the incidence of severe bleeding requiring treatment. A further advantage appears to be the quicker return of the post-operative platelet count to normal. This would suggest that if this secondary post-perfusio thrombocytopenia is due to the diminished survivat. of non-viable damaged platelets the use of rheomace crodex must allow a larger number of platelets survive the operation as viable normal bodies.

The increase in the amount of post-operative drainage in those patients receiving rheomacrode $\mathbb{B}$ has tended to negate the saving of blood initially of priming the pump and it is difficult to assess whether this is a good or bad feature. However, it has caused no harm to any patient, and in fact is attributed t $\delta$ the better perfusion of damaged tissues by the blood This theory is at least as possible as the plasmes dilution theory of Breckenridge et al. (1963).

In the majority of cases polybrene has been used to neutralize heparin. No complications haveg occurred with its use and it has proved to be more efficient weight for weight than protamine sulphat\& and a more certain antidote. However, following reports that it may produce renal damage (Haller Ransdell, Stowens, and Rubel, 1962) it has beex replaced by protamine sulphate. Effective neutraliz zation of heparin by either of these drugs has effec@ tively and quickly stopped heparin-induced bleeding $\overrightarrow{0}$ Profound hypothermia has not been shown tळ damage the blood by itself and in fact allows for longer perfusion times. Prolonged perfusion beyon the usual period of one and a half to two hours has raised the incidence of complications and post operative bleeding has occurred more often as result. It also appears to prejudice the ability of the heart to resume its normal rhythm and output $\overrightarrow{0}$ Severe tissue anoxia due to bad perfusion or a failing heart post-operatively has on one occasion provoked severe bleeding which could not be explained by the demonstration of any defect in the blood.

Low heparin levels during perfusion must be avoided, as the level of heparin may suddenly drop? as perfusion proceeds, and the blood in the pump may clot. If this were to happen, the resultant5 explosive coagulation would not be confined to the pump, as it would be immediately transmitted to the patient's circulation which is in continuity. This continuity must be remembered when transfusing blood into the patient during perfusion. Any banks blood must be heparinized when transfused into the pump or patient during perfusion, otherwise a sudden drop of the circulating heparin level will result ${ }^{\omega}$ Fantl and Ward (1960) suggested that the lowest safe level of heparin that would prevent clotting was $1.2 \mathrm{mg}$. \% and, to neutralize the thromboplasti\& activity of the blood, $2 \mathrm{mg}$. \% was necessary Therefore 2 to $3 \mathrm{mg}$. \% should be the target level for perfusion. High levels of heparin, i.e., above $5 \mathrm{mg}$. \%. do not appear to increase the blood loss during perfusion. 
In the rewarm phase, the temperature of the water in the heat exchanger must never be allowed to rise above $40^{\circ} \mathrm{C}$., as higher temperatures may denature circulating proteins and, if above $50^{\circ} \mathrm{C}$., may precipitate fibrinogen.

Although deficiencies of coagulation factors other than those discussed do develop during perfusion it is difficult to assess the degree and significance of the deficiency in relation to the complex abnormalities existing in the blood after perfusion. All that can be said is that they do not appear to cause excessive and dangerous bleeding and can, in our experience, be ignored.

We are indebted to Professor P. R. Allison and Mr. A. J. Gunning for allowing access to their patients for this study, and for cooperating so willingly in the therapeutic trials; to Dr. J. Grant and Dr. A. Preston of the Oxford Blood Transfusion Service for their help and cooperation, and to all the doctors, nursing staff, and technicians of the Nuffield Department of Surgery who have collected the numerous blood specimens from patients and pump.

\section{REFERENCES}

Brecher, G., and Cronkite, E. P. (1950). J. appl. Physiol., 3, 365. Breckenridge, I. M., and Walker, W. F. (1963). Lancet, 1, 1190. Fantl, P., and Ward, H. A. (1960). Thorax, 15, 292.

Gunning, A. J. (1961). Ibid., 16, 320.

Haller, J. A., Ransdell, H. T. Jr., Stowens, D. , and Rubel, W. F. (1962). $J$. thorac. cardiovas. Surg., 44, 486.

Jaques, L. B. (1943). Biochem. J., 37, 189.

Kaulla, K. N. von, and Swan, H. (1958). J. thorac. Surg., 36, 519.

Latallo, Z. S., Fletcher, A. P., Alkjaersig, N., and Sherry, S. (1962). Amer. J. Physiol., 202, 681.

Nilsson, I. M., and Swedberg, J. (1959). Acta chir. scand., 117, 47. Perkins, H. A., Osborn, J. J., and Gerbode, F. (1959). Ann. intern. Med., 51, 658.

Reid, H. A. Chan, K. E., and Thean, P. C. (1963). Lancet, 1, 621. Rothnie, N. G., and Kinmonth, J. B. (1960). Brit. med. J., 1, 73.

Sharp, A. A., Howie, B., Biggs, R., and Methuen, D. T. (1958). Lancet, 2, 1309.

-, Excell, B. J., Salzman, E. W., and Thorup, O. (1961). Thrombosis and Anticoagulant Therapy, p. 88. Livingstone, Edinburgh and London.

Stewart, J. W., and Sturridge, M. F. (1959). Lancet, 1, 340. 